\title{
DNMTs inhibitor SGI-1027 induces apoptosis in Huh7 human hepatocellular carcinoma cells
}

\author{
NING SUN, JIALIN ZHANG, CHENGSHUO ZHANG, BOCHAO ZHAO and AO JIAO \\ Department of Hepatobiliary and Transplantation Surgery, \\ The First Affiliated Hospital of China Medical University, Shenyang, Liaoning 110001, P.R. China
}

Received April 13, 2016; Accepted August 14, 2018

DOI: $10.3892 / \mathrm{ol} .2018 .9390$

\begin{abstract}
SGI-1027, a novel class of relatively stable, highly lipophilic quinoline-based small-molecule inhibitors of DNA methyltransferase enzymes (DNMTs), is able to inhibit DNMTs activity, and reactivate tumor suppressor genes. However, the potential anticancer mechanisms of SGI-1027 on human hepatocellular carcinoma (HCC) cells are still not clearly understood. Thus, the objective of the present study was to clarify the inhibitory effect of SGI-1027 on the cell cycle and apoptosis of the Huh7 cell line. The results revealed that treatment with SGI-1027 resulted in a significant dose-dependent decrease in cell viability. Flow cytometric analysis identified that a $24 \mathrm{~h}$ treatment of SGI-1027 resulted in cell apoptosis, and typical apoptotic nucleic alterations were observed with fluorescence microscopy following terminal deoxynucleotidyl-transferase-mediated dUTP nick end labeling staining. Immunoblot analysis further demonstrated that SGI-1027 downregulated the expression of B cell lymphoma-2 and upregulated the expression of $\mathrm{Bcl}$-associated $\mathrm{X}$ protein. However, no significant alterations of the cell cycle phases were observed. Overall, it is demonstrated that SGI-1027 causes cell apoptosis via the mitochondrial-mediated pathway, which advances current understanding of the molecular mechanisms of SGI-1027 in HCC management.
\end{abstract}

\section{Introduction}

Worldwide, primary liver cancer is more common in men than women, and is the second leading cause of cancer-associated

Correspondence to: Professor Jialin Zhang, Department of Hepatobiliary and Transplantation Surgery, The First Affiliated Hospital of China Medical University, 155 Nanjing Street, Shenyang, Liaoning 110001, P.R. China

E-mail: jlz2000@yeah.net

Abbreviations: HCC, hepatocellular carcinoma; DNMTs, DNA methyltransferase enzymes; TSGs, tumor suppressor genes; 5-aza-C, 5-azacytidine; 5-aza-dC, 5-aza-2-deoxycytidine

Key words: hepatocellular carcinoma, DNA methylation, SGI-1027, apoptosis mortality among men in poorly developed countries and the sixth in more developed countries (1). Although the diagnosis and the treatment of hepatocellular carcinoma (HCC) have been improved, the most efficient treatments for HCC are surgical removal of the tumor, and chemo- or radiotherapy. However, HCC is not sensitive to chemotherapy and easily develops resistance, which limits the application of chemotherapy in the clinic (2-4). Targeted therapy remains in an early stage of development, indeed, sorafenib has only a modest effect on patient survival (5). The aforementioned treatments have been demonstrated to be of limited efficacy and are not applicable to all patients (6). Thus, a novel antitumor agent with improved effectiveness may be a novel choice for the therapeutic treatment of HCC.

Researchers have identified that epigenetic alterations (in particular aberrant DNA methylation) were associated with the occurrence of a number of types of cancer (7). DNA methylation is an epigenetic modification of DNA performed by DNA methyltransferase enzymes (DNMTs), which catalyze the transfer of a methyl group from S-adenosyl methionine to the cytosine target nucleotide producing methylcytosine $(5 \mathrm{mC})(8)$. In the development of mammalian, DNA methylation serves a key function, which may affect gene repression, suppression of repetitive genomic elements, X-chromosome inactivation and parental imprinting $(9,10)$. The hypomethylation of repetitive elements results in genomic instability, while hypermethylation of the promoter is associated with tumor suppressor genes (TSGs) inactivation, affecting cell proliferation, apoptosis and DNA repair. The majority of cancer cells exhibit aberrant DNA hypermethylation localized in promoter regions, which are normally unmethylated and encode tumor suppressors (11). Aberrant DNA methylation may cause functional inactivation of these tumor suppressors and contribute to tumorigenesis (12). However, unlike other causes of gene inactivation, promoter methylation is a reversible process. Inhibitors of DNMTs may reactivate epigenetically silenced TSGs, decrease tumor cell growth and induce cell apoptosis. Therefore, DNMT inhibitors may be used as potential anticancer agents for cancer therapy (13-15).

Previously, certain DNMT activity inhibitors were evaluated in preclinical and clinical studies, including 5-azacytidine (5-aza-C), decitabine (5-aza-2'-deoxycytidine, 5-aza-dC), $1-\beta$-D-arabinofuranosyl-5-azacytosine, and dihydro-5-azacytosine (16). Decitabine has been approved by the Food and 
Drug Administration for the treatment of myelodysplastic syndrome (17). All these drugs are nucleoside inhibitors, able to incorporate into DNA and RNA, therefore they have certain drawbacks that include instability and relatively high toxicity $(18,19)$. SGI-110 (previously designated S110), a dinucleotide of 5-aza-2'-deoxycytidine and deoxyguanosine, containing a 5-azaCdR moiety has been demonstrated to be effective in inhibiting DNA methylation; however, its stability and cytotoxicity levels are similar to decitabine (20).

SGI-1027, a non-nucleoside DNMT inhibitor, has been reported as part of a novel class of relatively stable, highly lipophilic quinoline-based (monoquaternary pyridinium analogue) small-molecule inhibitors of DNMT1, DNMT3A and DNMT3B $(21,22)$. SGI-1027 may inhibit DNMT activity, induce the degradation of DNMT1 and reactivate TSGs; however, it is unable to bind to the RNA or the minor groove of DNA. To the best of knowledge, the effects of SGI-1027 on human HCC cells has not been previously researched, therefore the objective of the present study was to explore the effects of SGI-1027 on human HCC cells, understand the mechanisms of action of SGI-1027 and provide useful information for a possible application in HCC therapy.

\section{Materials and methods}

Preparation of SGI-1027. A $50 \mathrm{mmol} / 1$ stock solution of SGI-1027 (Selleck Chemicals, Houston, TX, USA) was prepared in dimethylsulfoxide (DMSO), which was used to prepare dosing solutions of 5, 10, 15, 20, 25, 30 and $35 \mu \mathrm{mol} / 1$ in culture medium, and $0.1 \%$ DMSO in the culture medium used as a control. The stock solution was kept at $-20^{\circ} \mathrm{C}$ for long term storage.

Cell culture. The human HCC cell line-Huh7 was purchased from the Cell bank of the Type Culture Collection of the Chinese Academy of Sciences (Shanghai, China). Huh7 cells were maintained in Dulbecco's modified Eagle's medium (DMEM; Invitrogen; Thermo Fisher Scientific, Inc., Waltham, MA, USA) supplemented with $100 \mathrm{U} / \mathrm{ml}$ penicillin, $100 \mu \mathrm{g} / \mathrm{ml}$ streptomycin and $10 \%$ fetal bovine serum (FBS; Life Technologies; Thermo Fisher Scientific, Inc.), and incubated in a humidified atmosphere containing $5 \% \mathrm{CO}_{2}$ at $37^{\circ} \mathrm{C}$.

MTS assay. Cell viability was measured using a CellTiter 96 Aqueous One Solution cell proliferation assay kit (Promega Corporation, Madison, WI, USA). Huh7 cells were seeded onto 96-well plates at a concentration of $1 \times 10^{4}$ cells/well and incubated in a humidified atmosphere containing $5 \% \mathrm{CO}_{2}$ at $37^{\circ} \mathrm{C}$ for $24 \mathrm{~h}$ in DMEM supplemented with $10 \% \mathrm{FBS}$. The Huh7 cells were subsequently treated with SGI-1027 (SGI-1027 was dissolved in DMSO) at different concentrations $(5,10$, $15,20,25,30$ and $35 \mu \mathrm{mol} / 1$, with $0.1 \%$ DMSO as a control). Cell viability was measured according to the manufacturer's protocol after $24 \mathrm{~h}$. An ELISA reader (BioTek Instruments, Inc., Winooski, VT, USA) was used to measure the absorbance value at $490 \mathrm{~nm}$. The viability ratio was calculated according to the following formula: [(The absorbance of experimental group-the absorbance of blank group)/(the absorbance of untreated group-the absorbance of blank group)] x100\%.
Cell cycle assay. The cell cycle was measured using a Cell Cycle Detection kit (KeyGen Biotech Co., Ltd., Nanjing, China). A total of $2 \times 10^{5} \mathrm{Huh} 7$ cells/well were seeded into a 6-well plate and starved in serum-free medium on the second day of culture. After $12 \mathrm{~h}$ starvation, the cells were treated with different concentrations of SGI-1027 (10,20 and $30 \mu \mathrm{mol} / \mathrm{l}$, and $0.1 \% \mathrm{DMSO}$ as control) for $24 \mathrm{~h}$. The cells were trypsinized and washed with cold PBS, then fixed overnight with $70 \%$ ethanol at $4^{\circ} \mathrm{C}$. The next day, the fixed cells were centrifuged at $1,200 \times \mathrm{g}$ at $4^{\circ} \mathrm{C}$ for $5 \mathrm{~min}$ and washed once with cold PBS. Subsequently, the cells were suspended in propidium iodide (PI)/RNase staining buffer at room temperature for $30 \mathrm{~min}$ in the dark according to the manufacturer's protocol. A FACScan flow cytometer (BD Biosciences, Franklin Lakes, NJ, USA) was used to analyze the DNA contents of the cells. Each measurement collected at least $1 \times 10^{4}$ cells.

Apoptosis assay. Cell apoptosis was assessed using the Annexin V-fluorescein isothiocyanate (FITC) apoptosis detection kit (KeyGen Biotech Co., Ltd.). A total of $2 \times 10^{5}$ Huh7 cells/well were seeded into a 6 -well plate. After $24 \mathrm{~h}$ exposures to different concentrations of SGI-1027 (10, 20 and $30 \mu \mathrm{mol} / 1$, with $0.1 \%$ DMSO as control), the cells were treated with $0.25 \%$ trypsin without EDTA. According to the manufacturer's protocols, Annexin V-FITC and PI were used for staining. The double-stained cells were measured using a FACScan flow cytometer (BD Biosciences). At least $1 \times 10^{4}$ cells were measured.

Terminal deoxynucleotidyl-transferase-mediated dUTP nick end labeling (TUNEL) assay. The TUNEL method was used to label apoptotic cells using a TUNEL apoptosis detection kit (KeyGen Biotech Co., Ltd.) according to the manufacturer's protocol. Following treatment with SGI-1027 at a number of concentrations $(10,20$ and $30 \mu \mathrm{mol} / 1$, with $0.1 \%$ DMSO as control) for up to $24 \mathrm{~h}$ in a humidified atmosphere containing $5 \% \mathrm{CO}_{2}$ at $37^{\circ} \mathrm{C}$ in a 6 -well plate, the cells were washed twice with PBS and fixed in $1 \mathrm{ml}$ of $4 \%$ paraformaldehyde for $10 \mathrm{~min}$ at $4^{\circ} \mathrm{C}$, and permeabilized with $0.1 \%$ Triton X100 at $25^{\circ} \mathrm{C}$ for $5 \mathrm{~min}$. The cells washed twice with PBS, stained by the TUNEL mixture for $1 \mathrm{~h}$ at $37^{\circ} \mathrm{C}$ in darkness, and then stained by the Streptavidin-Tetramethylrhodamine for $30 \mathrm{~min}$ at $37^{\circ} \mathrm{C}$ in darkness, followed by staining with DAPI at $37^{\circ} \mathrm{C}$ for $10 \mathrm{~min}$. The cells were washed with PBS, then mounted and examined using fluorescence microscopy (magnification, x200) (Olympus IX71; Olympus Corporation, Tokyo, Japan). Apoptotic cells were identified by the condensation and fragmentation of their nucleus. The apoptotic ratio was calculated using the following formula: Apoptotic cell number/seeded cell number $\mathrm{x} 100 \%$.

Western blot analysis. Huh7 cells were treated with SGI-1027 at different concentrations $(10,20$ and $30 \mu \mathrm{mol} / 1$, with $0.1 \%$ DMSO as control) for $24 \mathrm{~h}$, and then washed twice with ice-cold PBS and lysed in ice-cold protein lysis buffer containing $1 \%$ protease inhibitor cocktail and phenylmethylsulfonyl fluoride. The lysates were centrifuged at $10,000 \mathrm{x} \mathrm{g}$ for $10 \mathrm{~min}$ at $4^{\circ} \mathrm{C}$. Protein concentrations were determined using a bicinchoninic acid protein assay kit (Beyotime Institute of 
Biotechnology, Shanghai, China). Total proteins (25 $\mu \mathrm{g} / \mathrm{lane})$ were resolved using $12 \%$ SDS-PAGE, then transferred to polyvinylidene difluoride (PVDF) membranes using a wet transfer system (Bio-Rad Laboratories, Inc., Hercules, CA, USA) at $70 \mathrm{~V}$ at $4{ }^{\circ} \mathrm{C}$. The PVDF membranes were blocked with Tris-buffered saline plus Tween-20 (TBST; pH 8.0; Beijing Solarbio Science \& Technology Co., Ltd., Beijing, China) containing 5\% nonfat milk at room temperature for $1 \mathrm{~h}$, and then incubated with primary antibodies overnight at $4^{\circ} \mathrm{C}$. Subsequent to washing with TBST at room temperature (15 min/time, 3 times), membranes were incubated with horseradish peroxidase-conjugated Immunoglobulin $\mathrm{G}(\mathrm{IgG})$ at room temperature for $2 \mathrm{~h}$. The probed proteins were detected using an Enhanced Chemiluminescence kit (Beyotime Institute of Biotechnology) according to the manufacturer's protocol. The primary antibodies used in this study were rabbit anti-B cell lymphoma $(\mathrm{Bcl})-2$ polyclonal antibody (1:1,000; cat. no. 12789-1-AP; Proteintech Group, Inc. Chicago, IL, USA), mouse anti-Bcl associated X-protein (BAX) monoclonal antibody (1:1,000; cat. no. 60267-1-Ig; Proteintech Group, Inc.) and mouse anti- $\beta$-actin monoclonal antibody (1:1,000; cat. no. CW0096; CwBiotech, Beijing, China). The secondary antibodies included goat anti-rabbit IgG serum (1:20,000; cat, no. TA130015; OriGene Technologies, Inc., Beijing, China) and goat anti-mouse IgG serum (1:20,000; cat, no. TA130001; OriGene Technologies, Inc.). The images were analyzed using the MicroChemi Bio-Imaging system (DNR Bio-Imaging Systems Ltd., Neve Yamin, Israel) and quantified using Quantity One software (version 4.5.0; Bio-Rad Laboratories, Inc.).

Statistical analysis. All experiments were performed three times. The data were expressed as the mean \pm standard deviation. GraphPad Prism software (version 6.0; GraphPad Software, Inc., La Jolla, CA, USA) was used for data analysis. The differences were analyzed using a one-way analysis of variance test followed by Dunnett's test. $\mathrm{P}<0.05$ was considered to indicate a statistically significant difference.

\section{Results}

SGI-1027 inhibits the viability of Huh7 cells. In order to evaluate the effect of SGI-1027 on Huh7 cells, the cell viability was investigated using an MTS assay once Huh7 cells were dose-dependently treated with SGI-1027 for $24 \mathrm{~h}$. The results revealed that SGI-1027 significantly suppressed the cell viability of Huh7 cells in a dose-dependent manner compared with the DMSO control group, with an $\mathrm{IC}_{50}$ value of $27.30 \mu \mathrm{mol} / \mathrm{l}$ (Fig. 1).

SGI-1027 does not block the cell cycle of Huh7 cells. To investigate the effect of SGI-1027 on the cell cycle, the cell cycle profiles of Huh7 cells were analyzed using flow cytometry. However, no significant alterations of the cell cycle phases were observed following treatment with distinct concentrations of SGI-1027 for $24 \mathrm{~h}(\mathrm{P}>0.05)$. The percentage of cells accumulated in the $\mathrm{G} 1$ phase was $73.81 \pm 1.357,69.17 \pm 2.021$, $69.517 \pm 0.904$ and $72.547 \pm 2.724 \%$ in the DMSO control, 10, 20 and $30 \mu \mathrm{mol} / 1 \mathrm{SGI}-1027$ groups, respectively. The percentage of cells accumulated in the $S$ phase was $17.017 \pm 1.443$,

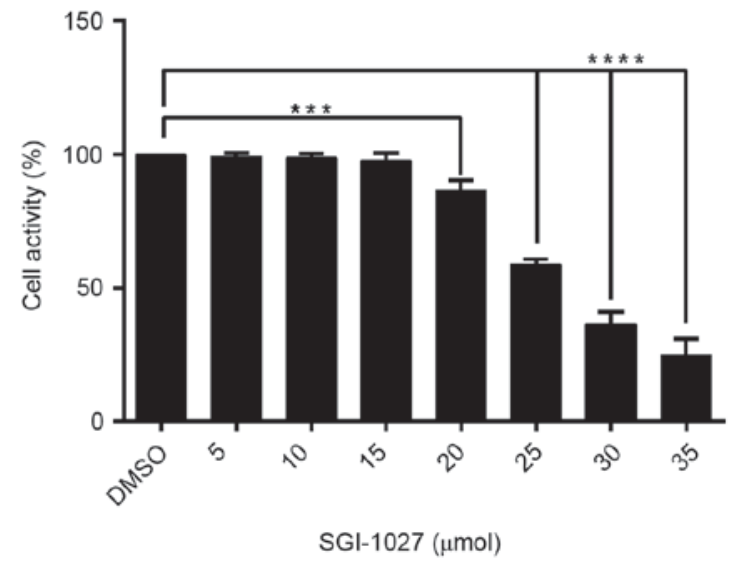

Figure 1. Effect of SGI-1027 on the viability of Huh7 cells treated with SGI-1027 for $24 \mathrm{~h}$. Cell viability was determined by using an MTS assay. ${ }^{* * *} \mathrm{P}<0.01$ and ${ }^{* * * *} \mathrm{P}<0.0001$, compared with the control group. DMSO, dimethyl sulfoxide.

$25.623 \pm 0.869,26.377 \pm 3.107$ and $14.140 \pm 1.067 \%$ in the DMSO control, 10, 20 and $30 \mu \mathrm{mol} / 1$ groups, respectively. The percentage of cells accumulated in the G2 phase was $8.377 \pm 1.542,3.577 \pm 1.452,4.633 \pm 0.503$ and $6.11 \pm 4.116 \%$ in the DMSO control, 10, 20 and $30 \mu \mathrm{mol} / 1$ SGI-1027 groups, respectively (Fig. 2).

SGI-1027 induces cell apoptosis in Huh7 cells. To confirm whether the SGI-1027 induced inhibition of proliferation was due to a direct effect on apoptosis in Huh7 cells, flow cytometry analysis was performed using Annexin V-FITC and PI double staining. It was identified that following dose-dependent treatment with SGI-1027 for $24 \mathrm{~h}$, in the control group there were normal cells and rarely apoptotic cells, while in SGI-1027 groups, the rates of apoptotic cells significantly increased in a dose-dependent manner. The rates of apoptosis in response to different concentrations of SGI-1027 were 3.242 \pm 0.204 (DMSO group), 3.672 $\pm 0.123(10 \mu \mathrm{mol} / \mathrm{l}), 33.49 \pm 1.317$ (20 $\mu \mathrm{mol} / \mathrm{l})$ and $46.57 \pm 2.512 \%(30 \mu \mathrm{mol} / \mathrm{l})$ (Fig. 3).

SGI-1027 induces morphological changes in Huh7 cells. In the present study, the apoptotic effects of SGI-1027 were ascertained in Huh7 cells by assessing morphological changes. Subsequent to treatment with different doses of SGI-1027 for $24 \mathrm{~h}$, Huh7 cells were stained with TUNEL. The results revealed that in the chromatin of apoptotic cells the fluorescence dye stains were observed more brightly compared with that of control cells. The number of Huh7 cells adhering to the culture plates in SGI-1027 treated groups was decreased compared with the control group. The morphological changes of cell apoptosis included blebbing, cell shrinkage, nuclear or chromatin condensation, DNA fragmentation and apoptotic body formation. In contrast, the morphology of normal cells was round and homogenous. In the present results, the apoptotic morphological changes were observed in the SGI-1027 treated groups, while few apoptotic cells were observed in the control group. The percentage of apoptotic cells was $0.987 \pm 0.34,3.883 \pm 0.667,42.44 \pm 3.244$ and $58.24 \pm 8.427 \%$ in the DMSO control, 10, 20 and $30 \mu \mathrm{mol} / 1$ SGI-1027 groups, respectively (Fig. 4). 


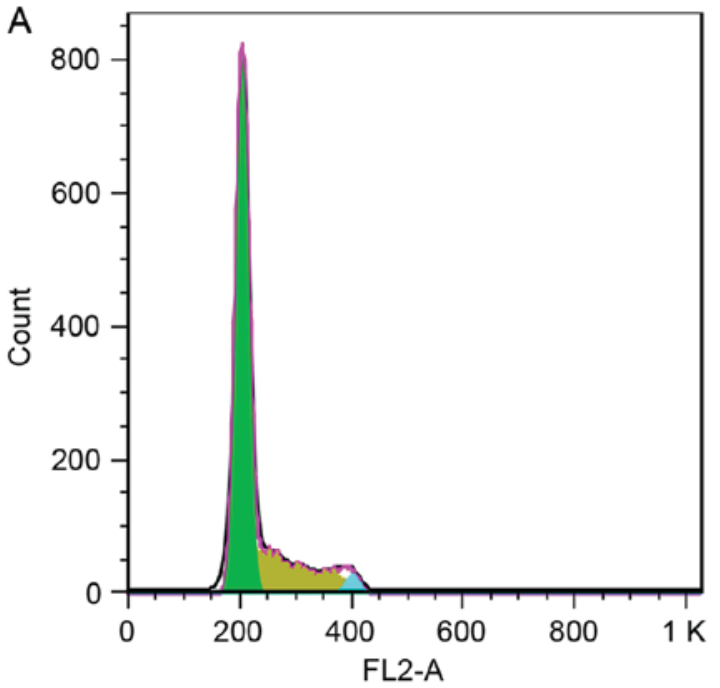

C

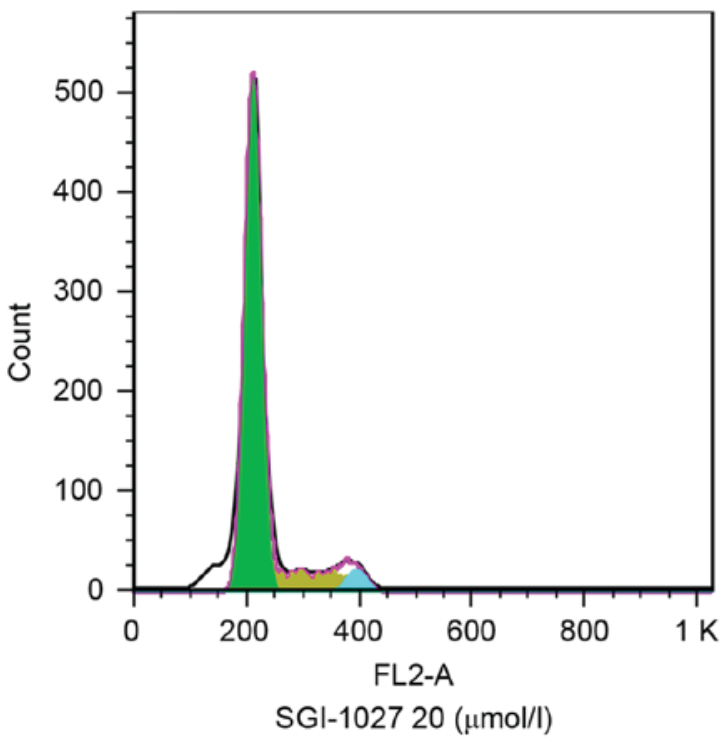

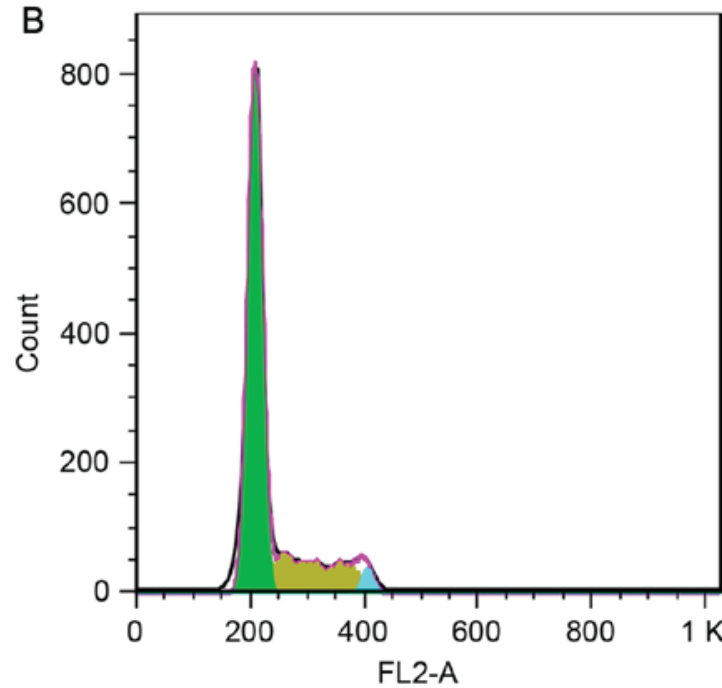

D

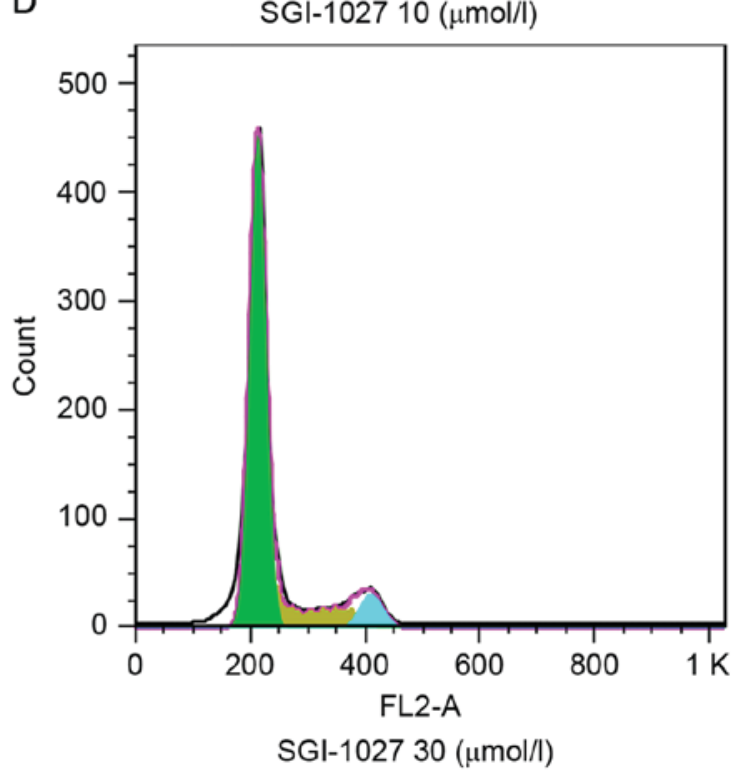

\begin{tabular}{l|l|l} 
Dip G1 Dip G2 & Dip S
\end{tabular}

Dip aggregates

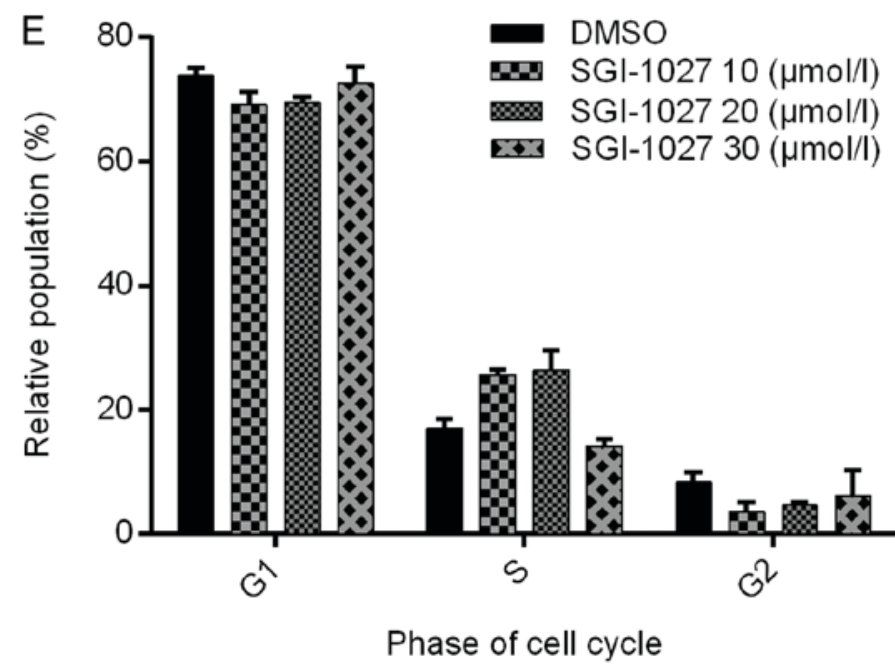

Figure 2. Effects of SGI-1027 on the cell cycle of Huh7 cells by flow cytometry. The cell cycle distributions in Huh7 cells were determined by propidium iodide staining and flow cytometric analysis following treatment with (A) $0.1 \%$ DMSO as a control, (B) $10 \mu \mathrm{mol} / 1$, (C) $20 \mu \mathrm{mol} / 1$ and (D) $30 \mu \mathrm{mol} / 1$ of SGI-1027 for $24 \mathrm{~h}$. (E) The ratios are expressed as the mean ratios \pm standard deviation of three independent experiments. Compared with the control group, respectively. DMSO, dimethyl sulfoxide. 

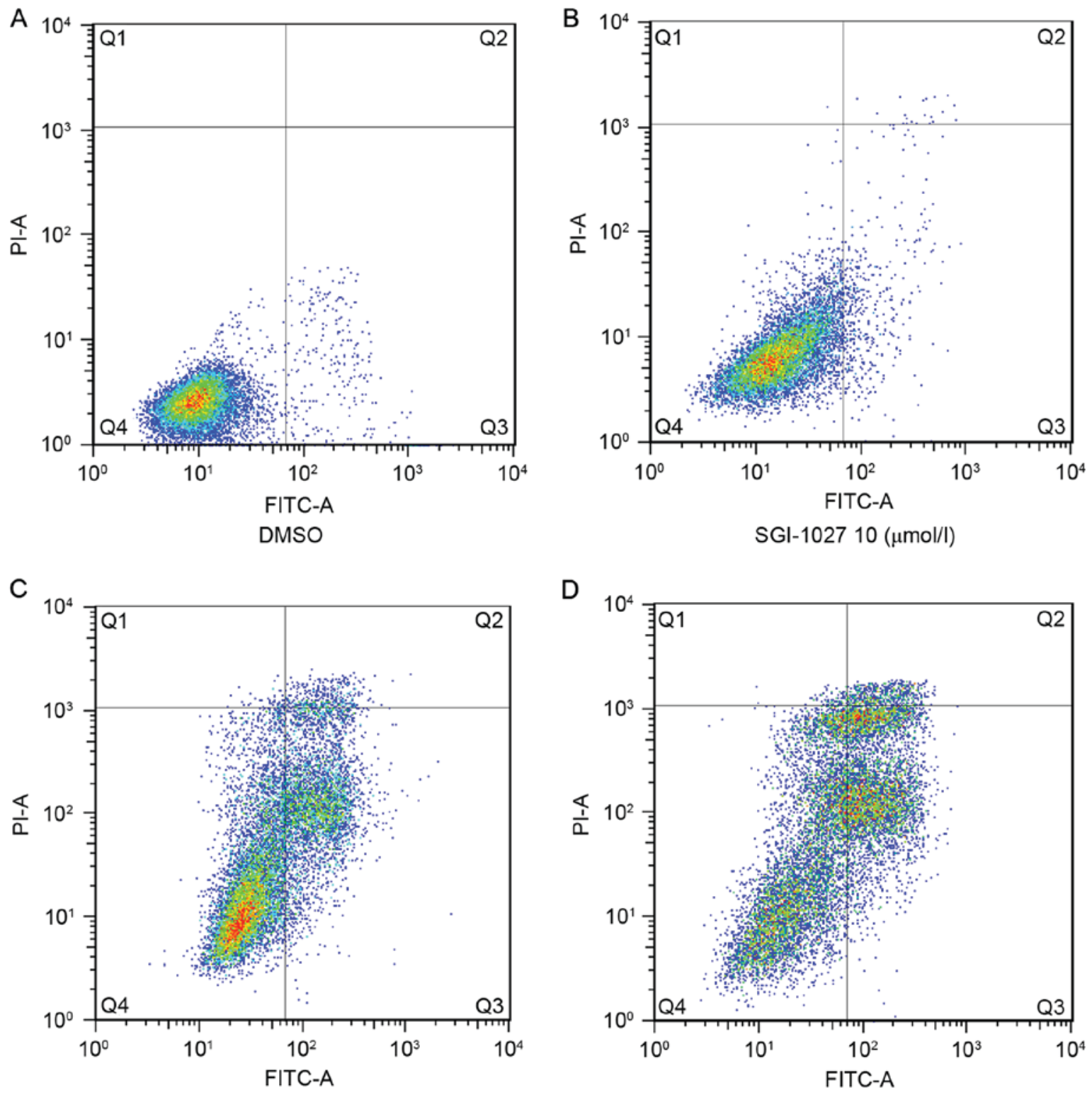

SGI-1027 $10(\mu \mathrm{mol} / \mathrm{l})$

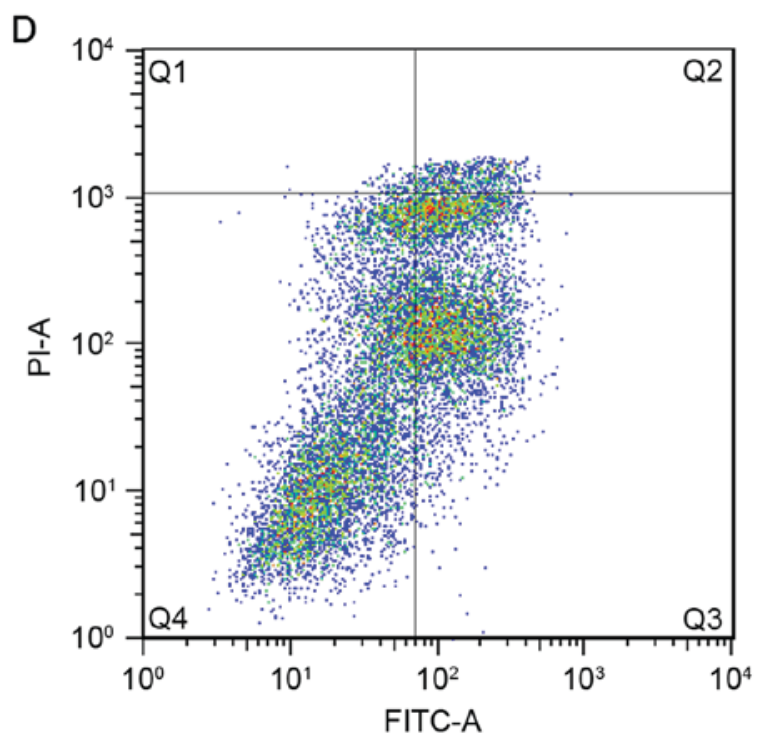

SGI-1027 $20(\mu \mathrm{mol} / \mathrm{l})$

SGI-1027 $30(\mu \mathrm{mol} / \mathrm{l})$

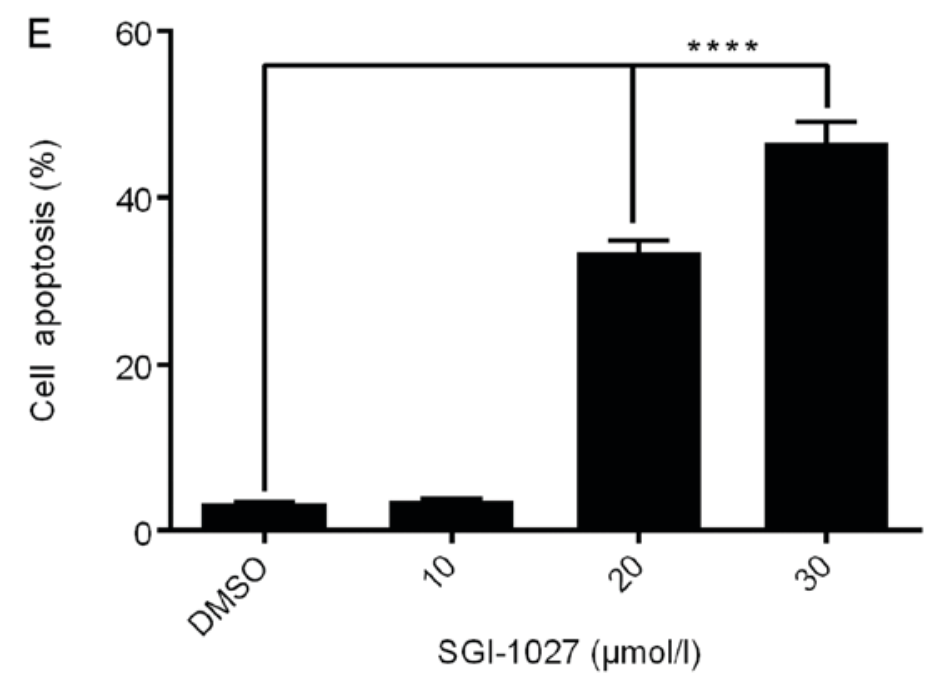

Figure 3. Effect of SGI-1027 on the apoptosis of Huh7 cells. Flow cytometric analysis for apoptosis with Annexin V-FITC and propidium iodide staining on Huh7 cells following treatment with (A) $0.1 \%$ DMSO as a control, (B) $10 \mu \mathrm{mol} / 1$, (C) $20 \mu \mathrm{mol} / 1$ and (D) $30 \mu \mathrm{mol} / 1$ of SGI-1027 for $24 \mathrm{~h}$. Annexin V-FITC was used to identify the early apoptotic cells and the late apoptotic cells were assessed by PI staining. (E) The ratios are expressed as the mean ratios \pm standard deviation. ${ }^{* * * * *} \mathrm{P}<0.0001$ vs. the control group. DMSO, dimethyl sulfoxide; FITC, fluorescein isothiocyanate. 


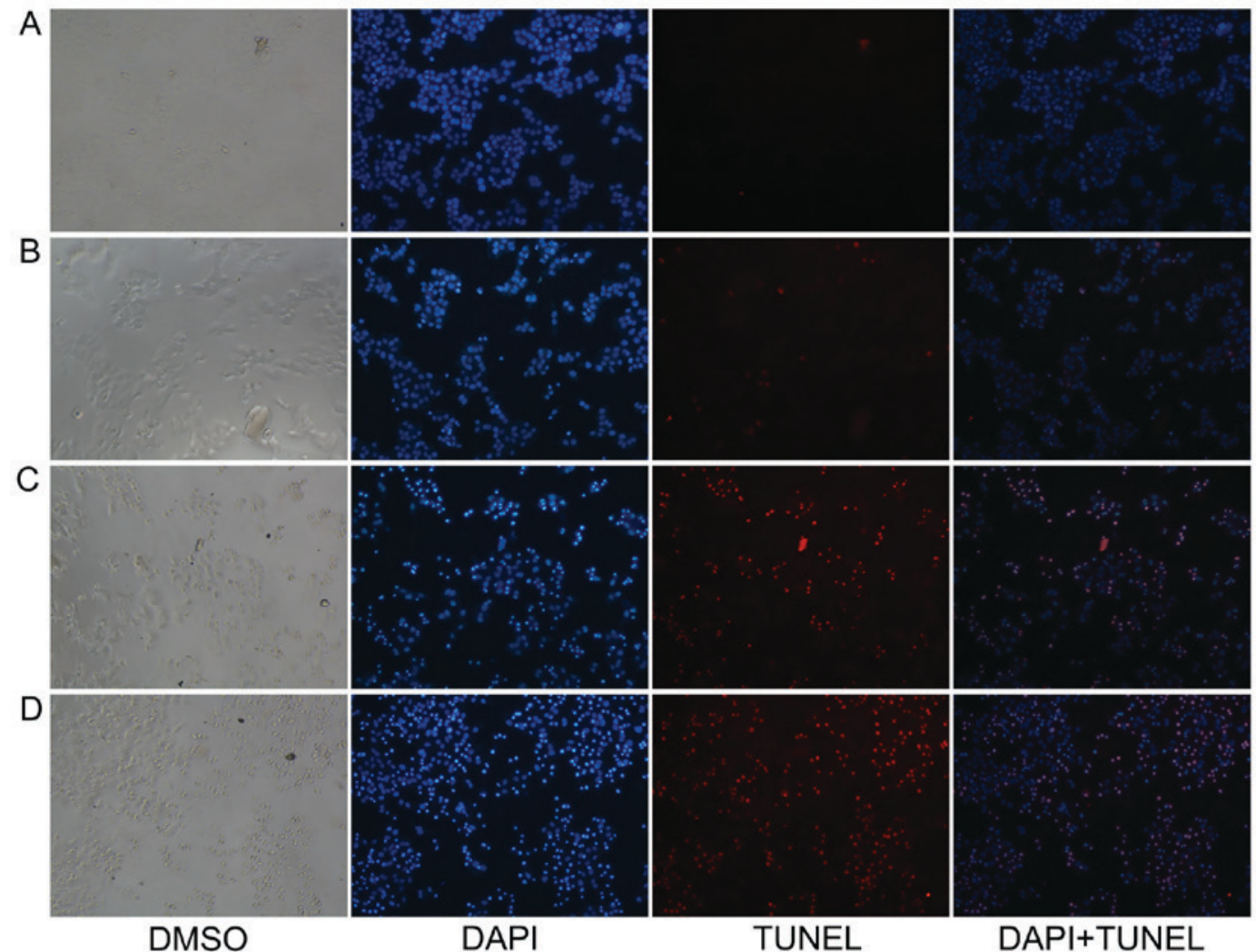

$E$

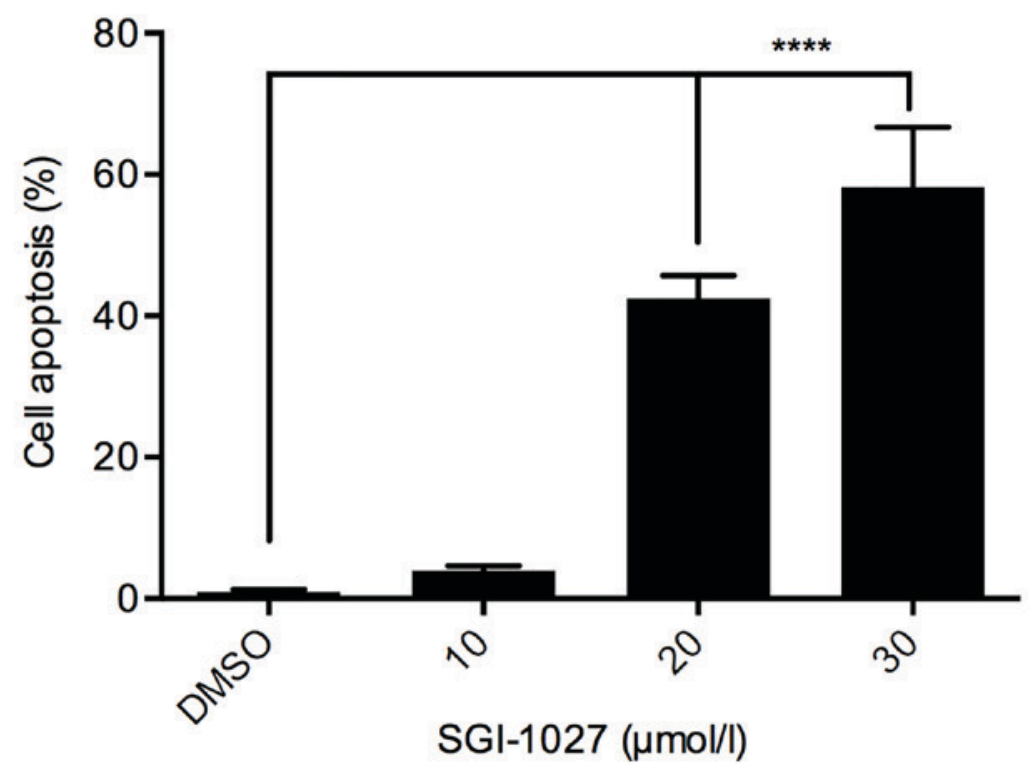

Figure 4. Effect of SGI-1027 on the morphological changes in Huh7 cells. TUNEL staining was used to observe the apoptotic cells under a fluorescence microscope (magnification, x200) following treatment with (A) $0.1 \%$ DMSO as a control, (B) $10 \mu \mathrm{mol} / 1$, (C) $20 \mu \mathrm{mol} / 1$ and (D) $30 \mu \mathrm{mol} / 1$ of SGI-1027 for $24 \mathrm{~h}$. TUNEL staining was used for observation of DNA fragmentation of Huh7 cells and DAPI staining was used to observe the total cells. (E) The values are expressed as the mean ratios \pm standard deviation from three independent experiments. ${ }^{* * * *} \mathrm{P}<0.0001 \mathrm{vs}$. the control group. DMSO, dimethyl sulfoxide; TUNEL, terminal deoxynucleotidyl-transferase-mediated dUTP nick end labeling.

SGI-1027 affects the expression of proteins associated with apoptosis. In order to investigate whether Bcl-2 and BAX expression were involved in the apoptosis of Huh7 cells, the expression levels of Bcl-2 and BAX were assessed using western blotting. The results indicated that following treatment with different concentrations of SGI-1027 (0.1\% DMSO as control, 10, 20 and $30 \mu \mathrm{mol} / 1 \mathrm{SGI}-1027), \mathrm{Bcl}-2$ protein expression was significantly downregulated, whereas BAX expression was significantly upregulated, in a dose-dependent manner, in Huh7 cells (Fig. 5).

\section{Discussion}

Epigenetic changes frequently occur in certain types of cancer via inactivation of TSGs, in particular, hypermethylation of the promoter region of genes is the most important 
A

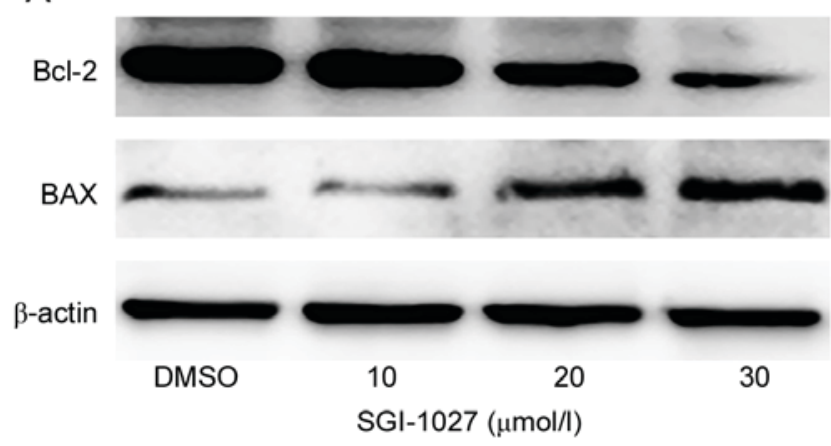

B

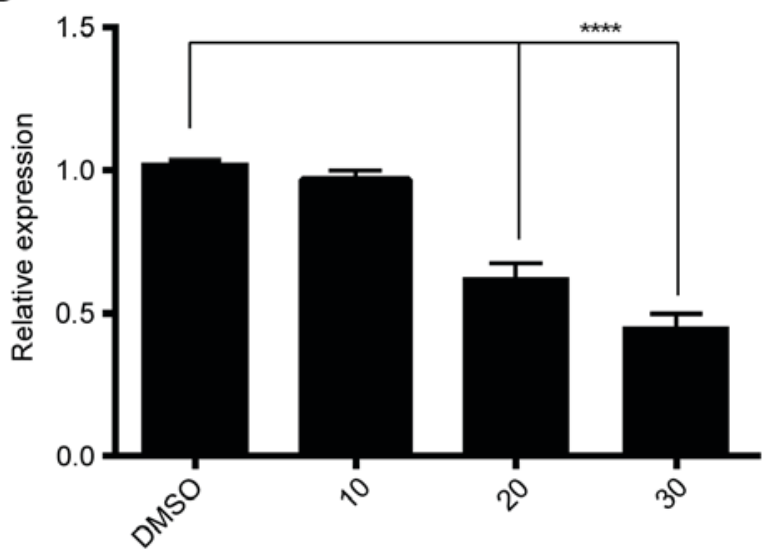

SGI-1027 ( $\mu \mathrm{mol} / \mathrm{l})$

C

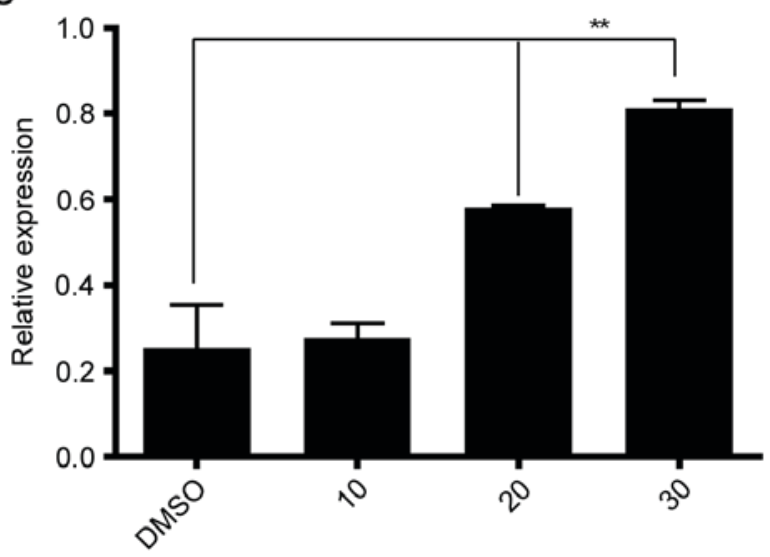

SGI-1027 ( $\mu \mathrm{mol} / \mathrm{l})$

Figure 5. Effect of SGI-1027 on the expression of apoptosis-associated proteins. (A) Bcl-2 and BAX protein expression levels were evaluated by western blotting in Huh7 cells treated with different concentrations $(0.1 \%$ DMSO as control, 10, 20, $30 \mu \mathrm{mol} / 1)$ of SGI-1027 for $24 \mathrm{~h}$. $\beta$-actin was used as a loading control. Quantification of (B) Bcl-2 and (C) Bax protein expression levels. The results are presented as the mean densitometric ratios \pm standard deviation in three independent experiments. ${ }^{* *} \mathrm{P}<0.01$ and ${ }^{* * * * * *} \mathrm{P}<0.0001$, vs. the control group. DMSO, dimethyl sulfoxide; Bcl-2, B cell lymphoma 2; BAX, Bcl-associated X protein.

epigenetic mechanism for silencing TSGs and causing tumorigenesis $(7,15,23,24)$. Unlike other gene expression mutations, methylation does not alter the DNA base sequence making DNA methylation reversible. An important component of the mammalian methylation machinery is DNMTs; therefore, DNMT inhibitors are considered as promising therapeutic targets (16).
Although DNA hypomethylating agents 5-aza-C and 5-aza-dC, and their analogues have been used in cancer therapy, their instability in solutions and toxicity have limited their clinical application, SGI-1027 is a quinolone-based small molecule non-nucleoside inhibitor, which is able to inhibit DNMTs and reactivate TSGs (21). Furthermore, it does not bind to the DNA or RNA, is relatively stable and exhibits lower toxicity compared with the nucleoside class DNMT inhibitors (21). To the best of our knowledge, four studies have investigated the inhibitory effect of SGI-1027 on DNMTs; however, the ability of SGI-1027 to inhibit proliferation and induce apoptosis in tumor cells remains scarcely studied $(21,22,25,26)$. One of the aforementioned studies, using citofluorimetric analysis, identified that SGI-1027 may induce apoptosis in human U937 cells; however, the study did not clarify the underlying molecular mechanism of apoptosis caused by SGI-1027 (25). There appears to be no research regarding the effects of SGI-1027 on human HCC cell lines.

In the present study, the MTS assay results revealed that SGI-1027 significantly inhibited the viability of Huh7 cells in a dose-dependent manner. Usually, the inhibition of cell viability involves blocking of cell cycle progression and apoptosis. However, in the present data, no significant alterations to the cell cycle phases were observed following SGI-1027 treatment. Although, the data demonstrated that SGI-1027 was associated with apoptosis in Huh7 cells. Flow cytometric analysis revealed that with increasing SGI-1027 concentrations, the early and late apoptotic cells proportions also increased. Furthermore, SGI-1027-treated Huh7 cells demonstrated significant apoptosis-associated morphological alterations.

The ability of cancer cells to inhibit apoptosis is essential for carcinogenesis. Programmed cell death has been identified as an effective mechanism to prevent cancer, and cell apoptosis is a core process of programmed cell death (27). The results of the present study suggested that Huh7 cells treated with SGI-1027 followed the typical apoptotic pathway. Bcl-2 family proteins have been suggested to be the primary regulators of apoptosis in the mitochondrial-mediated pathway, and BAX induced mitochondrial outer membrane permeabilization is considered as an important control switch of apoptosis (28). Bcl-2 is an anti-apoptotic protein, while BAX is a critical pro-apoptotic protein, which may increase the permeability of mitochondrial membranes and accelerate cell apoptosis $(29,30)$. In this research, it was demonstrated that SGI-1027 significantly downregulated Bcl-2 expression and upregulated BAX expression, suggesting that the apoptosis of Huh7 cells resulting from SGI-1027 occurred via the mitochondrial-mediated pathway.

In conclusion, the data gathered reveal that SGI-1027 inhibits Huh7 cell proliferation and induces apoptosis in vitro. We hypothesize that SGI-1027 may be able to reverse the aberrant DNA methylation of certain pro-apoptosis genes and trigger their re-expression. It is suggested that SGI-1027 may be a potential compound for the treatment of $\mathrm{HCC}$, providing a novel approach for HCC treatment. However, further research is required to elucidate the precise molecular mechanisms underlying the effects of SGI-1027 on apoptosis induction in $\mathrm{HCC}$, and assess the application of the present results to the treatment of human HCC. 


\section{Acknowledgements}

Not applicable.

\section{Funding}

The present study was supported by the science and technology project of Shenyang (grant no. F13-212-9-00).

\section{Availability of data and materials}

All data generated or analyzed during the present study are included in this published article.

\section{Authors' contributions}

JZ conceived the study. NS designed the study. NS, CZ, BZ and $\mathrm{AJ}$ performed the experiment. NS and $\mathrm{CZ}$ analyzed the data. NS wrote the manuscript.

\section{Ethics approval and consent to participate}

Not applicable.

\section{Patient consent for publication}

Not applicable.

\section{Competing interests}

The authors declare that they have no competing interests.

\section{References}

1. Torre LA, Bray F, Siegel RL, Ferlay J, Lortet-Tieulent J and Jemal A: Global cancer statistics, 2012. CA Cancer J Clin 65: 87-108, 2015

2. Yeo W, Mok TS, Zee B, Leung TW, Lai PB, Lau WY, Koh J, Mo FK, Yu SC, Chan AT, et al: A randomized phase III study of doxorubicin versus cisplatin/interferon alpha-2b/doxorubicin/fluorouracil (PIAF) combination chemotherapy for unresectable hepatocellular carcinoma. J Natl Cancer Inst 97: 1532-1538, 2005.

3. Gish RG, Porta C, Lazar L, Ruff P, Feld R, Croitoru A, Feun L, Jeziorski K, Leighton J, Gallo J and Kennealey GT: Phase III randomized controlled trial comparing the survival of patients with unresectable hepatocellular carcinoma treated with nolatrexed or doxorubicin. J Clin Oncol 25: 3069-3075, 2007.

4. Wang XQ, Ongkeko WM, Chen L, Yang ZF, Lu P, Chen KK, Lopez JP, Poon RT and Fan ST: Octamer 4 (Oct4) mediates chemotherapeutic drug resistance in liver cancer cells through a potential Oct4-AKT-ATP-binding cassette G2 pathway. Hepatology 52: 528-539, 2010.

5. Chua CW and Choo SP: Targeted therapy in hepatocellular carcinoma. Int J Hepatol 2011: 348297, 2011.

6. Dai ZJ, Tang W, Lu WF, Gao J, Kang HF, Ma XB, Min WL, Wang XJ and Wu WY: Antiproliferative and apoptotic effects of $\beta$-elemene on human hepatoma HepG2 cells. Cancer Cell Int 13: 27, 2013.

7. Esteller M: Epigenetic gene silencing in cancer: The DNA hypermethylome. Hum Mol Genet 16 Spec No 1: R50-R59, 2007.

8. Holliday R and Pugh JE: DNA modification mechanisms and gene activity during development. Science 187: 226-232, 1975.
9. Feng S, Jacobsen SE and Reik W: Epigenetic reprogramming in plant and animal development. Science 330: 622-627, 2010.

10. Bonasio R, Tu S and Reinberg D: Molecular signals of epigenetic states. Science 330: 612-616, 2010.

11. Feinberg AP and Tycko B: The history of cancer epigenetics. Nat Rev Cancer 4: 143-153, 2004.

12. Herman JG and Baylin SB: Gene silencing in cancer in association with promoter hypermethylation. N Engl J Med 349: 2042-2054, 2003.

13. Sharma S, Kelly TK and Jones PA: Epigenetics in cancer. Carcinogenesis 31: 27-36, 2010.

14. Taby R and Issa JP: Cancer epigenetics. CA Cancer J Clin 60: 376-392, 2010.

15. Kondo Y: Epigenetic cross-talk between DNA methylation and histone modifications in human cancers. Yonsei Med J 50: 455-463, 2009.

16. Ghoshal K and Bai S: DNA methyltransferases as targets for cancer therapy. Drugs Today (Barc) 43: 395-422, 2007.

17. Oki Y, Aoki E and Issa JP: Decitabine-bedside to bench. Crit Rev Oncol Hematol 61: 140-152, 2007.

18. Gorbunova V, Seluanov A, Mittelman D and Wilson JH: Genome-wide demethylation destabilizes CTG.CAG trinucleotide repeats in mammalian cells. Hum Mol Genet 13: 2979-2989, 2004.

19. Mund C, Hackanson B, Stresemann C, Lübbert M and Lyko F: Characterization of DNA demethylation effects induced by 5-Aza-2'-deoxycytidine in patients with myelodysplastic syndrome. Cancer Res 65: 7086-7090, 2005.

20. Yoo CB, Jeong S, Egger G, Liang G, Phiasivongsa P, Tang C, Redkar S and Jones PA: Delivery of 5-aza-2'-deoxycytidine to cells using oligodeoxynucleotides. Cancer Res 67: 6400-6408, 2007.

21. Datta J, Ghoshal K, Denny WA, Gamage SA, Brooke DG, Phiasivongsa P, Redkar S and Jacob ST: A new class of quinoline-based DNA hypomethylating agents reactivates tumor suppressor genes by blocking DNA methyltransferase 1 activity and inducing its degradation. Cancer Res 69: 4277-4285, 2009.

22. Gros C, Fleury L, Nahoum V, Faux C, Valente S, Labella D, Cantagrel F, Rilova E, Bouhlel MA, David-Cordonnier MH, et al: New insights on the mechanism of quinoline-based DNA Methyltransferase inhibitors. J Biol Chem 290: 6293-6302, 2015.

23. Palii SS and Robertson KD: Epigenetic control of tumor suppression. Crit Rev Eukaryot Gene Expr 17: 295-316, 2007.

24. Kulis M and Esteller M: DNA methylation and cancer. Adv Genet 70: 27-56, 2010.

25. Garcia-Dominguez P, Dell'aversana C, Alvarez R, Altucci L and de Lera AR: Synthetic approaches to DNMT inhibitor SGI-1027 and effects on the U937 leukemia cell line. Bioorg Med Chem Lett 23: 1631-1635, 2013.

26. Ronen M, Avrahami D and Gerber D: A sensitive microfluidic platform for a high throughput DNA methylation assay. Lab Chip 14: 2354-2362, 2014.

27. Elmore S: Apoptosis: A review of programmed cell death. Toxicol Pathol 35: 495-516, 2007.

28. Renault TT, Teijido O, Antonsson B, Dejean LM and Manon S: Regulation of Bax mitochondrial localization by Bcl-2 and Bcl-x(L): Keep your friends close but your enemies closer. Int J Biochem Cell Biol 45: 64-67, 2013.

29. Hata AN, Engelman JA and Faber AC: The BCL2 family: Key mediators of the apoptotic response to targeted anticancer therapeutics. Cancer Discov 5: 475-487, 2015.

30. Siddiqui WA, Ahad A and Ahsan H: The mystery of BCL2 family: Bcl-2 proteins and apoptosis: An update. Arch Toxicol 89: 289-317, 2015.

This work is licensed under a Creative Commons Attribution 4.0 International (CC BY-NC 4.0) License 